\title{
Crecimiento económico, declinación del desarrollo político y tecnocracia en Chile: Lecciones para el nuevo ciclo político post estallido
}

\author{
Economic Growth, Declining Political Development and Technocracy in \\ Chile: Lessons for the New Political Cycle After the Social Outbreak
}

\author{
Carlos Huneeus Madge ${ }^{1}$
}

\begin{abstract}
Cómo citar este artículo: Huneeus Madge, C. (2021). Crecimiento económico, declinación del desarrollo político y tecnocracia en Chile: Lecciones para el nuevo ciclo político post estallido. Revista de Ciencias Sociales Ambos Mundos, (2), 19-35. https://doi. org/10.14198/ambos.20989
\end{abstract}

\begin{abstract}
Resumen
El trabajo analiza los factores que explicarían el contraste que hubo entre el buen desempeño económico de los gobiernos de la Concertación de Partidos por la Democracia (1990-2010) en Chile y un decreciente desarrollo político. Este contraste se explica por decisiones estratégicas adoptadas por la tecnocracia del primer gobierno democrático del presidente Patricio Aylwin (1990-1994) y continuada por quienes le sucedieron, y en particular, haber optado más por la continuidad que por la reforma del sistema económico heredado de la dictadura. Esta decisión tuvo enorme relevancia política porque corresponde a una economía de mercado puro en la tipología de Linz y Stepan (1996), la cual consideran incompatible con la democracia moderna. El estallido social del 18 de octubre de 2019 fue la máxima expresión de esa incompatibilidad. El trabajo identifica los factores de poder de la tecnocracia y los errores cometidos por esta.
\end{abstract}

Palabras claves: Crecimiento económico; desarrollo político; tecnocracia; Chile.

\section{Abstract}

The work analyzes the factors that would explain the contrast that existed between the good economic performance of the governments of the Concertación de Partidos por la Democracia (1990-2010) in Chile and a decreasing political development. This contrast is explained by strategic decisions adopted by the technocracy of the first democratic government of President Patricio Aylwin (1990-1994) and continued by those who succeeded him, and in particular, having opted more for continuity than for the reform of the economic system inherited from the dictatorship. This decision had enormous political relevance because it corresponds to a pure market economy in the Linz and Stepan (1996) typology, which they consider incompatible with modern democracy. The social outbreak of October 18, 2019, was the maximum expression of that incompatibility. The work identifies the power factors of the technocracy and the mistakes made by it.

Keywords: Economic Growth; Political Development; Technocracy; Chile.

1. Carlos Huneeus Madge, Universidad de Chile, Chile. chuneeus@derecho.uchile.cl https://orcid.org/0000-0002-3278-9208

Fecha recepción: 22/09/2021, Fecha aceptación: 07/10/2021

Licencia: Este trabajo está sujeto a una licencia de Reconocimiento 4.0 Internacional de Creative Commons (CC BY 4.0).

https://creativecommons.org/licenses/by/4.0/ 


\section{INTRODUCCIÓN ${ }^{1}$}

El presente trabajo analiza los factores que explicarían el contraste que hubo entre el buen desempeño económico de los gobiernos de la Concertación de Partidos por la Democracia (1990-2010) -alto y sostenido crecimiento, reducción de la pobreza e inflación de un dígito- y un desarrollo político que, por el contrario, no fue de la mano con aquel, sino que fue decreciente -caída la participación electoral, debilitamiento y fraccionamiento del sistema de partidos, baja satisfacción con la democracia y baja confianza hacia las instituciones y las élites políticas-, conduciendo a una crisis de representación (Castiglioni y Rovira-Kaltwasser, 2016; Luna, 2016 y 2017; Osorio, 2019). El objeto del estudio es la participación de los partidos en el gobierno, un tema descuidado por la bibliografía que analiza la región de América Latina y en particular de Chile. El interés de la investigación no es primeramente descriptivo, al dar cuenta de los pormenores del contraste antes indicado, sino principalmente explicativo, al buscar identificar los factores que explican dicho contraste y sus consecuencias en el sistema político.

Lo que se sostiene es que el contraste entre el crecimiento económico y el desarrollo político tiene que ver con decisiones adoptadas por la tecnocracia en los gobiernos de la Concertación, la que tomó grandes decisiones e impulsó políticas que tendrán importantes consecuencias en la evolución institucional del país, particularmente en el debilitamiento del desarrollo político y los partidos políticos. Estuvo formaba por profesionales mayoritariamente economistas, que ocuparon la dirección de los principales ministerios. Seis de los veinte ministros del gobierno de Aylwin (1990-1994) eran economistas, cuatro de los cuales tenían doctorado en prestigiosas universidades de EE.UU. y Europa occidental y los otros dos habían sido decanos de la facultad de Economía de la Universidad de Chile, la principal universidad del país ${ }^{2}$. Los economistas fueron ministros de las tres carteras más directamente vinculadas con su profesión -Hacienda, Economía y Planificación y Desarrollo-, además de otras tres relevantes: Secretaría General

1. Agradezco a Alejandro Osorio Rauld y a Manuel Délano por sus comentarios y la cuidadosa edición de una versión anterior.

2. El ministro de Transporte tenía un doctorado en sociología en una prestigiosa universidad de la costa oeste de los EE.UU. de la Presidencia, la colaboradora más cercana del presidente, Educación y Obras Públicas ${ }^{3}$. Por otro lado, muchos de estos actores tenían una militancia, aunque pasiva, en algunos de sus partidos, y se constituyeron en el principal grupo de poder en el gobierno, tomando decisiones exitosas respecto a los objetivos económicos, aunque con efectos adversos en el desarrollo político en términos de la participación electoral, las orientaciones políticas de la ciudadanía y el estado de los partidos.

No obstante, la decisión más importante que nos interesa ilustrar en este artículo, fue la de optar más por la continuidad que por la reforma del sistema económico heredado de la dictadura, que corresponde a una economía de mercado puro en la tipología de Linz y Stepan (1996), la cual consideran incompatible con la democracia moderna. Esta decisión se justificó con argumentos económicos -dar una señal de confianza a los empresariospara que se mantuviera el crecimiento económico que venía desde 1985 y conseguir resultados económicos positivos que beneficiarían a corto plazo la imagen del gobierno en la población. Esta decisión, reafirmada cuando la izquierda llegó a La Moneda el 2000, con Ricardo Lagos (2000-2006), el primer socialista después de Salvador Allende (PS), y en el de Michelle Bachelet (PS) (2006-2010), implicaría que la transformación económica de la dictadura siguiendo un paradigma de neoliberalismo radical, se consolidaría en democracia por gobiernos de coalición de centro-izquierda, proporcionando al sistema económico una cierta legitimación de la cual carecía por su pecado original de haber sido impuesto por la dictadura.

El artículo se desarrolla de la siguiente manera. Primeramente, se define el objeto de la investigación y se formula la tesis que la guiará, resaltando el contraste entre el crecimiento económico

3. Además, dos de los seis presidentes de partidos en 1990 eran economistas, el de la UDI, el principal de oposición, con un master de economía en la Universidad de Chicago, y el del PS, abogado y master en economía en la Universidad de Harvard. El presidente del PDD en tres ocasiones en los años 90 y 2000 fue un ingeniero civil y con un master en economía en la Universidad de Harvard. Por último, pero no menos importante, dos de los cinco presidentes desde 1990 fueron economistas: Ricardo Lagos (2000-2006), abogado y doctorado en la Universidad de Duke, y Sebastián Piñera (2010-2014; 2018-2022), economista, con un doctorado en esta disciplina en la Universidad de Harvard. 
y el menor desarrollo político, lo cual tiene que ver con decisiones de la tecnocracia y los legados de la dictadura. Luego, se expone el marco teórico y los conceptos siguiendo a Caramani (2017), que permiten explicar el poder de la tecnocracia. En la tercera parte, se analizan las bases de poder de la tecnocracia y su protagonismo en la democratización, destacando su decisión por dar continuidad al sistema económico impuesto por la dictadura guiado, como se dijo, por un paradigma de neoliberalismo radical (“el modelo"). Esta decisión tuvo amplias consecuencias políticas, porque fue un giro en 180 grados respecto a la posición de los partidos durante la dictadura, que criticaron severamente su política económica: esta decisión, en definitiva, perjudicaría a los partidos de la Concertación, pues les impidió mostrar a sus electores su perfil progresista, perdiendo votantes por desencanto y frustración y reforzando la baja confianza en los partidos, otro legado de la dictadura. Las conclusiones cerrarán el capítulo.

\section{CRECIMIENTO ECONÓMICO Y DEBILITAMIENTO DEL DESARROLLO POLÍTICO}

En efecto, el sistema económico en la tipología de Linz y Stepan (1996), se caracteriza por establecer una extrema libertad de mercado, aleja al Estado de las actividades económicas y no se preocupa de la provisión, directa o a través de privados, de los bienes sociales de salud, educación, pensiones y vivienda para hacer posible un mínimo bienestar a la población. El "modelo" de los Chicago Boys reunía esos componentes institucionales, que continúan tensionando al sistema democrático, con inestabilidad política que amenaza su continuidad. Agregan, además, que la democracia requiere una "sociedad económica", que la definen por tener mecanismos institucionales que median entre el Estado y el mercado, en la que el primero tiene una activa participación en la economía, controla los monopolios y está preocupado de las desigualdades. La sociedad económica tiene una importancia capital en la estabilidad de la democracia, particularmente ante crisis económicas, que no la posee la economía de mercado puro, "Si una democracia nunca produjera políticas que generarán bienes públicos auspiciados por el gobierno en las áreas de educación, salud y transporte, una red de seguridad para sus ciudadanos dañados por im- portantes bandazos del mercado y cierto alivio de desigualdades extremas, la democracia no sería sostenible" (Linz y Stepan, 1996, pp. 12-13).

Para que Chile tenga una democracia moderna, es decir, avance desde una democracia semisoberana a una democracia soberana (Huneeus, 2014), requiere tener una "sociedad económica", lo significa impulsar reformas al sistema económico siguiendo un paradigma distinto del neoliberal que tuvo la dictadura. Como veremos en este trabajo, las reformas que se hicieron al sistema económico, especialmente durante el gobierno de Aylwin, no se guiaron por otro paradigma.

En efecto, la incompatibilidad entre el sistema económico y el sistema político se puso en evidencia en conflictos sociales que han remecido el sistema político en dos oportunidades: en las masivas movilizaciones estudiantiles de 2011 contra la educación superior, por su alto costo y el endeudamiento de miles de familias, y en el estallido social del 18 de octubre de 2019. Este última fue un conflicto más amplio porque las demandas ciudadanas fueron contra diversas industrias y situaciones negativas acumuladas (pensiones, la educación y la salud, la colusión de precios por empresas y contra empresas que proveen bienes públicos). La intensidad del conflicto social hizo temer que el presidente Sebastián Piñera no terminaría su mandato presidencial en marzo de 2022 (Huneeus y Pastén, 2020). Las desigualdades de ingreso, con una pequeña minoría que concentra la riqueza y una inmensa mayoría de la población que tiene condiciones de vida muy difíciles, constituye otra importante fuente de tensiones y conflictos sociales, acentuados en situaciones de crisis, como la del estallido social, y se manifiestan demandas por reformas que apunten hacia una menor distancia entre los superricos y el conjunto de la población (Inglehart, 2016).

En el caso chileno, la opción por la continuidad del "modelo" significó, además, ignorar los componentes políticos de la transformación económica de la dictadura, que siguió un paradigma de neoliberalismo radical que tuvo una visión totalizante, pues modificó las bases del Estado, la sociedad y la economía, estableciendo otras en las cuales el mercado tuvo un lugar central. Además, no fue neutral políticamente, pues tuvo objetivos políticos bien definidos: contribuir a la legitimación de la dictadura por el desempeño económico, debilitar las bases sociales de los partidos de centro e izquierda, constituir una amplia y cohesionada base de apoyo en el empresariado y favorecer las 
bases sociales de los partidos de derecha para cuando los militares regresaran a sus cuarteles (Huneeus, 2000; Huneeus y Undurraga, 2021). Y, en tercer lugar, favoreció la continuidad de rasgos estructurales que caracterizaron "la revolución capitalista chilena" (Gárate, 2012), entre los cuales destacaba la concentración económica en pocos y poderosos grupos económicos, reforzando una realidad que se dio antes del golpe militar, como lo demostró el ex presidente Lagos en su memoria de grado (Lagos, 1960); también, las desigualdades de ingreso, que, como argumentan varios autores, tienen raíces políticas y son fuente de conflictos sociales. Ellas también amenazan la estabilidad de la democracia (Inglehart, 2016).

Para evitar incurrir en un reduccionismo al papel de las élites, se sostiene que el poder alcanzado por la tecnocracia tiene que ver no solo a sus credenciales académicas y profesionales, sino también con factores institucionales, que se encuentran en los cambios en la organización de los partidos de oposición durante la dictadura. Estos cambios entregaron a los centros privados independientes (CPI), en los cuales trabajaron los tecnócratas, dos importantes funciones de los partidos, siguiendo la tipología de Wolinetz (2002): la preparación del programa alternativo de gobierno a la dictadura (policy seeking) y el reclutamiento de los profesionales que serían ministros y altos funcionarios del futuro gobierno democrático y, por tanto, responsables de implementar el programa (office seeking). Los partidos limitaron su función a la tercera de acuerdo a Wolinezt: prepararse para ganar las elecciones para llegar al gobierno (vote seeking). Este cambio daría a los investigadores de los centros de estudios enorme poder e influencia en la preparación del programa de la Concertación y en la formación del gabinete del presidente Aylwin.

Esta decisión tuvo amplias repercusiones en las capacidades de los partidos, pues dejaron de ocuparse del desarrollo de las ideas que orientan la competencia política, reduciendo su labor a participar en las campañas electorales. También dejaron de preocuparse del reclutamiento de profesionales para ocupar altos cargos en el gobierno y de candidatos al Congreso y a los gobiernos comunales, recurriendo al pequeño grupo de dirigentes de los partidos desde los años de la dictadura. El énfasis en los cambios organizativos de los partidos como responsables del poder de la tecnocracia permite un análisis más específico de los factores institucionales que explican el contraste por factores institucionales más amplios del sistema político (Garretón, 2012).

Por lo anterior, nuestra tesis no reduce la responsabilidad del contraste entre crecimiento económico y menor desarrollo político a las decisiones y comportamiento de los tecnócratas. También la tienen los partidos de la coalición de gobierno por las decisiones adoptadas en la dictadura antes mencionadas y que no corrigieron en democracia. En particular, descuidaron su organización, la cual, siguiendo a Scarrow y Webb (2013), fue débil, porque tuvieron una baja autonomía respecto de liderazgos individuales; se produjo una alta centralización decisoria y concentración territorial, que limitaron las posibilidades de implantación en los distintos territorios. Y, por último, se descuidó su relación con el movimiento sindical y estudiantil, que había sido muy potente antes del golpe militar y que volvería a serlo desde los años 80 del siglo pasado hasta el gobierno de Aylwin.

Por otra parte, los partidos tuvieron una extrema precariedad de recursos financieros, porque no hubo financiamiento público hasta la ley de 2015. Estos vieron disminuidas sus capacidades organizativas, pues no contaron con financiamiento para tener una oficina central o secretaría nacional con personal profesional pagado y a tiempo completo, especialmente para apoyar a la directiva nacional en el desempeño de sus funciones de entregar orientaciones políticas y evaluar la acción del gobierno, elementos que tienen los partidos de las democracias avanzadas (Mair, 1994). Esto debilitó las funciones fundamentales que deben asumir los partidos de gobierno, como es proporcionar ideas para diseñar las policies y proponer a personas para ocupar los altos cargos (Mair, 2015; Strom, 2000). En efecto, la ausencia de financiamiento público de los partidos durante un cuarto de siglo dañó severamente el desarrollo político, pues empujó a las colectividades de la Concertación a recurrir al patronazgo del Estado y al financiamiento privado, lo que llevó a tener una baja autonomía respecto del gobierno y de sus donantes, con consecuencias en las políticas y en una legislación amistosa con el poder económico, además que incentivó el tráfico de influencias y la corrupción. Los partidos de oposición de derecha (RN y la UDI) tendrán una estrecha relación con el sector privado, lo cual les permitió disponer de amplísimo financiamiento en sus campañas electorales, muy superior al que tuvieron los partidos de la Concertación (Agostini, 2012). 


\section{EL CONTRASTE ENTRE EL BUEN DESEMPEÑO ECONÓMICO Y LA DECLINACIÓN DEL DESARROLLO POLÍTICO}

Los gobiernos de la Concertación tuvieron un buen desempeño económico, especialmente durante el gobierno del presidente Aylwin. La inflación bajó a un digito, la pobreza fue reducida drásticamente del $40 \%$ en 1988 al $13,9 \%$ en 2009 , y hubo un crecimiento sostenido, todo lo cual permitió que los chilenos tuvieran mejores condiciones de vida como nunca antes en su historia (Ffrench-Davis, 2018; Muñoz, 2007). También, el país sobresalió respecto de la gestión de los primeros gobiernos de las nuevas democracias de América Latina, que concluyeron sus mandatos desbordados por la hiperinflación, el desempleo y el aumento de la pobreza. Chile fue considerado por los organismos económicos internacionales (FMI, Banco Mundial) como "un modelo" en América Latina, digno de imitar por otros países.

Sin embargo, los buenos resultados económicos no fueron acompañados por resultados políticos positivos. Se produjo una disminución de la participación electoral, que comenzó con las elecciones parlamentarias de 1997. En las elecciones presidenciales de 1989 votó el 84,2\% de la población en edad de votar, que bajó al $71,8 \%$ en la primera vuelta de las presidenciales de 1999. En las siguientes elecciones la participación volvió a bajar llegando al $46,8 \%$ en la primera vuelta de las elecciones presidenciales de 2017 (Morales, 2018). Esta participación electoral está por debajo del piso considerado para la legitimación de la democracia a través de elecciones, que Lijphart (2001) sitúa en el 50\%.

Los partidos de la Concertación se debilitaron. En las elecciones de 1989 alcanzaron 48,98\% del electorado, destacando el PDC, con 25,99\%. En las elecciones de 2017, los cuatro partidos recibieron una considerable menor votación, 29,8\%, desplomándose la $\mathrm{DC}$ al 10,3\%. También bajó la votación del PPD al $6,1 \%$ y se mantuvo la del PS, 9,8\%. Esta caída contrasta con la notable estabilidad de RN y la UDI, recibiendo 33,2\% de la votación en 1989 y 33,8\% en 2017 (Morales, 2018).

Junto con el debilitamiento electoral de los partidos del centroizquierda, se ha producido una fragmentación del sistema de partidos, por conflictos y divisiones internas que llevaron a la fundación de nuevas colectividades, y al surgimiento de otras, a partir de las movilizaciones estudiantiles de 2011 contra la política de educación superior de los gobiernos de la Concertación. De las seis colectividades con representación parlamentaria que surgieron en las elecciones de 1989 (cuatro de la Concertación y dos de derecha), el número de partidos con representación parlamentaria aumentó a 13 en las elecciones del 2013 y a 17 en las elecciones de $2017^{4}$. La fragmentación ocurrió especialmente en la izquierda, pues de tres partidos se aumentó a once. Este alto número de partido complejiza la gobernabilidad de la democracia por la diversidad de intereses que deben agregar, lo cual se acentúa por el hecho que ningún partido tiene un apoyo electoral que le permita cumplir una función de liderazgo en el sistema político, sea de gobierno o de oposición. La consecuencia de ello es una baja capacidad decisoria del sistema político, dificultando su desempeño.

El contraste entre el buen desempeño económico y la declinación del desarrollo político fue advertido tempranamente por Linz y Stepan (1996), quienes analizando los resultados de encuestas del CERC, observaron que, a pesar de los muy buenos indicadores económicos y la alta popularidad del presidente Aylwin, se produjo una baja satisfacción con el desempeño de la democracia, que cayó del $75 \%$ alcanzado en agosto de 1990 , pocos meses después de su inauguración, al 37\% tres años más tarde. Estos datos subjetivos, agregaron, estarían indicando que "la democracia podría estar perdiendo a los ojos de los ciudadanos algo de su atractivo y hasta de su legitimidad" (Linz y Stepan, 1996, p. 217).

Linz y Stepan (1996) atribuyeron este hecho al protagonismo del general Pinochet, que mantuvo una persistente actitud de bloquear las iniciativas del gobierno Aylwin de hacer verdad y justicia por las violaciones a los Derechos Humanos, llevando a cabo actos de provocación que llegaron al borde de la insurrección militar, como fue "el boinazo" en 1993. Sin embargo, también es cierto que la satisfacción con la democracia no aumentó cuando Pinochet abandonó la comandancia en jefe del Ejército en 1998 y después de su muerte en 2006. Por tanto, el factor Pinochet no es relevante para explicar el contraste. Al contrario, sí lo es el poder de los tecnócratas en los gobiernos de la Concertación.

\footnotetext{
4. En las elecciones de 2013 se incluye al PC, que no consiguió escaños hasta las de 2009 por impedirlo el Sistema Electoral Binominal.
} 


\section{EL PODER DE LA TECNOCRACIA}

El argumento sobre la impacto de la tecnocracia de los gobiernos de la Concertación en el desarrollo político se inspira en algunos postulados de Daniele Caramani (2017), quien Ilamó la atención sobre los efectos perjudiciales de la tecnocracia en las democracias modernas por el alto poder alcanzado, influyendo en la definición de la agenda de los gobiernos, de las prioridades de su políticas (policies) y en su implementación, influyendo no sólo en la marcha del gobierno, sino de todo el sistema político, llegando a constituir una representación política especial que es antagónica con la representación política de partidos, que es propia de la democracia (Caramani, 2017).

Caramani (2017) desarrolló esta cuestión con argumentos que nos parecen persuasivos para analizar la responsabilidad de la tecnocracia en el contraste entre crecimiento económico y debilitamiento del desarrollo político en Chile desde 1990. De acuerdo a este autor, la tecnocracia concibe la política de una manera singular, sin considerar la mediación y las estructuras de intermediación, los partidos y los grupos de interés, por lo cual desconocen las importantes funciones que cumplen estas organizaciones en el sistema político. La tecnocracia evalúa su desempeño con indicadores objetivos definidos por el gobierno, sin considerar la evaluación subjetiva que hace la ciudadanía de su labor, que puede ser distinta a la realidad entregada por los indicadores objetivos (p. 54). Por ello, la tecnocracia no considera la competencia política, una dimensión fundamental de la política democrática (Schumpeter, 1984).

Este punto es muy relevante para el caso de Chile, porque al llegar al gobierno la tecnocracia vinculada a la Concertación tenía una evaluación crítica del estado de los partidos por el conocimiento que tenía de su organización y por la experiencia del gobierno de la Unidad Popular del presidente Allende (1970-1973). En aquel gobierno, los partidos de la Unidad Popular (CUP) tuvieron enorme poder, interviniendo en el nombramiento de ministros y en definiciones de políticas, decisiones propias del presidente. En un memorándum del 28 de agosto de 1989, Edgardo Boeninger, encargado de preparar el programa de gobierno de la Concertación, manifestó al entonces candidato presidencial, Patricio Aylwin, su preocupación porque una de las restricciones del futuro gobierno estaría en "el riesgo de que los diferentes partidos de la Concertación reaccionan de manera contradictoria ante las dificultades en virtud de diferen- cias de sensibilidad, de diversidad de posiciones doctrinarias o de cálculos de conveniencia político-electoral" ${ }^{5}$. En un memorándum posterior, del 5 de diciembre de 1989, Boeninger rechazaba crear una instancia extra parlamentaria "como un comité de partidos de la coalición", teniendo en cuenta la experiencia del CUP del gobierno de Allende ${ }^{6}$.

En segundo lugar, la tecnocracia tiene una visión negativa de los partidos, considerándolos vehículos de intereses particulares, no del conjunto de la sociedad. Esto se manifiesta en su organización, constituida por facciones individualistas, que articulan intereses específicos. Los partidos bajo su mirada no tendrían la capacidad para formular visiones y proyectos para el bien común de la sociedad. Esto contrasta con la visión que tienen los tecnócratas de sí mismos, convencidos de poseer los conocimientos para saber qué se debe hacer y poseer las habilidades para definir a implementar las políticas. Así, los cuadros tecnopolíticos destacan la "centralidad de la especulación racional para identificar las metas de una sociedad y los medios para implementarlas" (Caramani, 2017, p. 54). Esta perspectiva desconoce la naturaleza de la política, que es compleja y dinámica, en la cual hay imprevisión, incertidumbre y puzzle (Pierson, 1993).

En tercer lugar, la tecnocracia concibe la política sin el pueblo, porque los ciudadanos no tienen las capacidades para conocer las cuestiones generales de la política, que solo ella posee. Además, desconoce la pluralidad que caracteriza la política democrática, pues la reduce a "la oposición entre lo correcto y lo errado" (Caramani, 2017, p. 64). Por tanto, promueve soluciones únicas, sin plantearse alternativas, lo que lleva necesariamente a una despolitización o impedir el debate público, ya que no se permite al ciudadano valorar la relevancia de las elecciones, ante la imposibilidad de percibir las diferencias entre los candidatos.

5. Repositorio Digital Archivo Patricio Aylwin Azócar, "Gestión de Gobierno y Proceso de decisiones púbicas. Memorándum Nr. 1, (Edgardo Boeninger, 28 de agosto de 1989), en: http://www2.archivopatricioaylwin.cl/bitstream/handle/123456789/8173/ APA-3063. pdf?sequence $=1$ \&isAllowed $=($ consultado el 28 de julio de 2021).

6. Repositorio Digital Archivo Patricio Aylwin Azócar, “Gestión de Gobierno y Proceso de decisiones púbicas. Memorándum Nr. 2 (versión revisada; 5 de Diciembre de 1989), en: http://www2.archivopatricioaylwin.cl/ handle/123456789/8458, (consultado el 28 de julio de 2021) 
El enfoque de Caramani (2017) proporciona un marco conceptual y teórico que no poseen los estudios que han destacado el papel de los tecnócratas o 'tecnopols' (Domínguez, 1997; Puryear, 1994) en el caso chileno ${ }^{7}$. Estos tenían altas credenciales académicas de posgrado en prestigiosas universidades de los EE.UU. y de Europa occidental, la mayoría fueron investigadores en los centros privados de investigación y fueron militantes de partidos de oposición a la dictadura.

Los tecnócratas fueron elogiados por la gestión económica, que habría sido decisiva en el éxito de la democratización. En ese sentido, por ejemplo, Patricio Silva (2008, p. 191), afirmó que "los grupos tecnocráticos han desempeñado un papel fundamental en facilitar su consolidación". Joignant (2011, p. 518) fue aún más lejos, concluyendo que "el éxito electoral sostenido de la Concertación y de sus dos décadas en el gobierno, se debieron en una dimensión significativa a la existencia de un cohesionado grupo de tecnopols que operó bajo condiciones que fueron heredadas del régimen anterior de Pinochet, pero que también fue modificado por sus acciones". Finalmente, en una dirección similar, Dávila (2020, p. 25) argumentó que la tecnocracia constituyó uno de los principales poderes informales que hizo posible el presidencialismo de coalición, junto al suprapartidismo, la proporcionalidad y la transversalidad.

Antes bien, la solidez explicativa de estos estudios, desde nuestra perspectiva, es discutible. Ellos ponen demasiada atención en los antecedentes académicos y profesionales de los tecnócratas (sociología de las élites) y les atribuyen habilidades políticas, sin indicar cuáles fueron y cómo se manifestaron. Asumen que tuvieron un amplio poder e influencia en los gobiernos, incurriendo en una especie de explicación monocausal reducida a sus habilidades personales, sin considerar los factores contextuales que lo explican, como fue su poder adquirido en la oposición a la dictadura y el liderazgo del presidente Aylwin. Este último factor tiene enorme importancia porque el presidente Aylwin estaba convencido de la importancia de la gestión económica para el éxito de su gobierno y se preocupó de ayudar a la labor del equipo económico, especialmente en discursos y declaraciones de prensa llamando a la ciudadanía y a las organizaciones de trabajadores a moderar sus expectativas económicas. Además, analizan

7. Montesinos (1990; 1998); Puryear (1994); Silva (2008); Joignant (2011); Dávila (2020); Arriagada y Graham (1994). el desempeño económico de la tecnocracia como si hubiese sido constante en los cuatro gobiernos, sin distinguir sus diferencias internas; se examinan las policies que impulsaron, pero se hace desde una perspectiva estrictamente económica, sin considerar sus orientaciones políticas, que influyeron en forma decisiva en sus deliberaciones. Por último, tampoco consideran las consecuencias de las policies en el proceso político, particularmente en la competencia política y en los partidos.

En contraste, nuestra tesis asigna responsabilidad a la tecnocracia en la debilidad del desarrollo político chileno, porque adoptó decisiones que fueron determinantes en la orientación de los gobiernos de la Concertación y en las prioridades de su agenda.

Destacan tres decisiones estratégicas adoptadas por la tecnocracia de la Concertación, estrechamente vinculadas entre sí, y respaldadas por los partidos de gobierno: 1) la estrategia de consolidación de la democracia por el desempeño económico; 2) la opción por la continuidad del sistema económico heredado ("el modelo"); y 3) la política del consenso permanente. Estas decisiones fueron tomadas fundamentalmente por los economistas de Cieplan, el principal centro de estudios independientes durante la dictadura, fundado en 1976 y vinculado al PDC (Huneeus, Cuevas y Hernández, 2014; Morales Ibáñez, 2018). Su presidente fue desde entonces Alejandro Foxley, ingeniero químico con un doctorado en la Universidad de Wisconsin, Madison, que fue ministro de Hacienda en el gobierno de Aylwin; otro economista del Cieplan fue ministro del Trabajo y una decena de investigadores ocuparon altos cargos en ambos ministerios, en la Dirección de Presupuesto y en el Banco Central (Gárate, 2012; Silva, 2008). Estas decisiones perduraron durante los cuatro gobiernos de la coalición de centroizquierda, provocando una inercia institucional que quitó capacidad de interpretar el malestar que surgió en la sociedad con el sistema económico, que fue visible a partir de las elecciones parlamentarias de 1997 (Huneeus, 1998; Mayol, 2019).

Estas decisiones configuraron el paradigma de acción del gobierno, expresado en el programa de "crecimiento con equidad" del gobierno de Aylwin y "crecimiento con igualdad" del gobierno de Lagos. El presidente Aylwin respaldó este programa, aunque tuvo una aproximación crítica a la economía de mercado, inspirado en la doctrina social de la Iglesia, la cual, como católico practicante que era, conocía muy bien. Dio algunas señales de ello en declaraciones públicas al comienzo del gobierno, 
como aquella "el mercado es cruel", que fue contradicha por Foxley, quien declaró "la política es más cruel". Esas afirmaciones expresaban las dos almas que convivieron en los gobiernos de la Concertación. La del político, que conocía sus reglas y prácticas porque había estado en ella durante medio siglo, y la del tecnócrata, que tenía una prolongada biografía académica ${ }^{8}$.

El paradigma es un recurso empleado por los policymaker, constituido por un marco de ideas y estándares que especifica los fines de la política, indica la naturaleza de los problemas a los que apuntan y señala el tipo de instrumentos que debieran ser usados para alcanzar esos objetivos (Hall, 1993). En general, los países siguen un paradigma en sus políticas económicas, que les da coherencia a sus programas y a su ejecución, y poseen flexibilidad para enfrentar nuevos desafíos. Sin contar con un paradigma, la acción de gobierno no tiene la capacidad para dar un perfil propio a su gestión, su labor tenga coherencia y transmitir a los ciudadanos la novedad de sus resultados (Hall, 1993). Ejemplo de paradigma fue el keynesianismo.

Los paradigmas, agrega Hall, no son rígidos en el tiempo, pueden transmitir o tener capacidad para enfrentar nuevos desafíos, para lo cual introducen cambios a las políticas que han impulsado y a las instituciones establecidas durante su formulación original. Tres son los tipos de cambios de los paradigmas. El primero se refiere a los instrumentos de la política económica, por ejemplo, la tasa de interés mínima, el equilibro fiscal tolerado (modificados en varias oportunidades, por ejemplo, en Gran Bretaña entre 1970 y 1989 por los gobiernos laboristas y conservadores). Esos cambios no alteran los objetivos generales y los instrumentos de la política económica (Hall, 1993, p. 278). El segundo tipo de cambios son aquellos que modifican las técnicas básicas empleadas para alcanzar los objetivos, como consecuencia de la insatisfacción con los resultados alcanzados. Finalmente, un tercer cambio de orden significa reformas en los objetivos, instrumentos y las orientaciones del paradigma vigente y

8. Foxley recordó este episodio en sus entrevistas-memorias con las periodistas Stipicic y Barría (2017: 73) “(...) le llegó una invitación para inaugurar el mall Alto Las Condes, y avisó que no iba a ir, que nunca había entrado a un mall y que no pensaba hacerlo. Me avisaron y dijeron que tendría que ir yo. Eso te da una idea de ese punto de vista algo más visceral que él tenía, que venía de una tradición republicana más cercana al Estado". apuntan a su reemplazo por otro paradigma (Hall, 1993, p. 278).

Pues bien, en el caso chileno, la primera decisión consistió en acordar una estrategia de legitimación del nuevo orden político en torno al desempeño económico, con el convencimiento que éste produciría bienes políticos (Montero, 1993). Así, la tecnocracia en cuestión reconocía el hecho que, en el corto plazo, la estabilidad democrática dependía de la subordinación de los militares a la autoridad civil y de la actitud del general Pinochet al respecto. Sin embargo, a mediano y largo plazo, ella se definiría por la gestión económica, con cinco millones de pobres, el $40 \%$ de la población que había que reducir. Está decisión impuso la primacía de alcanzar los objetivos económicos por sobre objetivos propiamente políticos, entre los cuales destacaba el problema militar, con la continuidad del general Pinochet como comandante en jefe el ejército (Huneeus, 2014).

Quienes tomaban las decisiones seguían la antigua tesis de la teoría de la modernización de los años 60 del siglo pasado, uno de cuyos exponentes fue Seymour M. Lipset (1959), quien señalaba que “mientras más desarrollada sea una nación, mayores serán las posibilidades que sostendrá la democracia" (Lipset, 1960, pp. 59-50). No se consideró, entonces, la complejidad de las relaciones entre política y economía, sin existir evidencia robusta que confirmara el aporte significativo del crecimiento económico en el desarrollo político.

La tecnocracia ignoró la naturaleza esencialmente política de las decisiones económicas, pues estas son adoptadas por los gobiernos, que son "creaturas políticas" (Hall, 1986, p. 4). La política consiste en tomar decisiones sobre intereses contrapuestos, que son articulados por grupos de presión e individuos, que abogan por sus intereses en distintas arenas institucionales y empleando diversos recursos, existiendo, a su vez, escasos medios para satisfacer esos intereses. De ahí que "la formación de las políticas económicas debe ser vista como un proceso altamente político" (Hall, 1986, p. 4). Esta afirmación no desconoce el hecho de que la gestión económica implique tomar decisiones sobre ciertas materias complejas, que requieren el conocimiento especializado de los expertos, pero sus propuestas son evaluadas por los políticos, que las pueden contradecir, puesto que existen bienes políticos que defender, como es, por ejemplo, conseguir la adhesión de los votantes (Hall, 1986, p. 274).

Por otra parte, el peso de la "memoria colectiva' también contribuyó a esta situación, ya que la 
izquierda cargaba con la culpa de la mala gestión económica del gobierno de la Unidad Popular del presidente Salvador Allende, que agravó la crisis política que condujo al golpe militar (Bermeo, 1992). Ahora, sus dirigentes querían mostrar que habían aprendido la lección y que se tenían los conocimientos técnicos y la voluntad política para una participación responsable en el gobierno. A ello también contribuyó, como se ha dicho, su formación académica, con estudios de posgrado sobre todo en Estados Unidos (y en menor medida en Europa), lugar simbólicamente relevante en la proliferación de cuadros técnicos altamente preparados para administrar los Estados bajo una lógica economicista o neoliberal (Dezalay y Garth, 2002).

Edgardo Boeninger, el influyente ministro Secretario General de la Presidencia de Aylwin ${ }^{9}$, resumió esta estrategia en un documento interno del gobierno tres semanas después de haberse constituido, destacando el hecho de que la agenda propiamente política de la transición debía quedar en segundo plano: "El Gobierno debe pasar de la etapa épica de los acontecimientos dramáticos que marcaron la lucha que llevó al poder a una fase de mayor rutina y cotidianidad... Promover desde el gobierno y hacerse parte del clima cultural del desarrollo... Este no es un gobierno puramente "político-democrático" ocupado exclusivamente del poder y la distribución. Su norte es el desarrollo del país, el país moderno, más integrado, más equilibrado socialmente (subrayado mío, citado por Walker, 2020, p. 137-138).

Varios años después, fuera del gobierno, Boeninger reiteró la necesidad de que la política económica constituyera al centro de la estrategia de consolidación democrática: “Una estrategia política

9. Boeninger tenía un enorme prestigio en los partidos de gobierno y en la oposición. Ingeniero y economista, fue decano de la Facultad de Ciencias Económicas de la Universidad de Chile y rector de esta universidad (1969-1973). Fue director de Presupuesto durante el gobierno de Frei Montalva. En dictadura fue director del CED (Centro de Estudios del Desarrollo), fundado por Gabriel Valdés en 1981 y llegó a ser uno de los vicepresidentes del PDC (1987-1989), acompañando a Patricio Aylwin, elegido presidente de la colectividad. Dotado de gran inteligencia y una extraordinaria capacidad de retener antecedentes muy variados, tuvo, sin embargo, los límites de la tecnocracia, guiándose por una lógica de racionalidad, sin advertir las complejidades de la política. Cometió importantes errores, como sostener, en agosto de 1991, que la transición había terminado. Esta afirmación la reitera en sus memorias (Boeninger, 1997). diseñada para lograr la consolidación de la democracia exigía un diagnóstico de cuáles serían los factores que determinarían -al final del periodo de transición- el juicio ciudadano sobre el éxito gubernativo que asegurara la continuidad democrática y, naturalmente, de la coalición en el poder. Se concluyó, con razón demostrada en los hechos, que dicho juicio se iba a jugar en el campo económico-social más que en el político-institucional" (subrayado mío, Boeninger, 2007, p. 35).

Sin embargo, Boeninger no consideró el "problema militar", el más complejo en las transiciones (Stepan, 1988), más grave en Chile que en los demás países de América Latina, por la continuidad del general Pinochet en la dirección del Ejército (Agüero, 1995), asumiendo que el gobierno tenía la autonomía para conducir la economía, sin ser perturbado por el ex dictador. Las provocaciones de Pinochet contra el gobierno, los partidos de izquierda y las organizaciones de Derechos Humanos, dañaron la imagen de la democracia, cayendo en la encuesta de agosto la satisfacción con la democracia, como advirtieron Linz y Stepan (1996) en su capítulo sobre Chile.

\section{LA DECISIÓN POR LA CONTINUIDAD DEL "MODELO"}

La segunda decisión estratégica fue la de optar más por la continuidad que por la reforma profunda del sistema económico heredado de la dictadura. Hemos dicho que fue la más importante de las tres decisiones adoptadas por la tecnocracia, porque tuvo amplias repercusiones políticas, respecto al pasado y respecto al futuro. Respecto al pasado, significó un giro en 180 grados respecto a la política de sus partidos durante la dictadura, cuando criticaron severamente su política económica y anunciaron cambiar el "modelo" una vez recuperada la democracia. Además, rompía la historia reformista del PDC, el PS y el PR de aspirar a salir del subdesarrollo y alcanzar una sociedad más igualitaria, que fueron los objetivos de los gobiernos de Pedro Aguirre Cerda (PR) (1938-1941), de Eduardo Frei Montalva (PDC) (1964-1970) con ta "revolución en libertad" (Huneeus y Couso, 2016) y de Salvador Allende, con la "vía chilena al socialismo" (Bitar, 1979).

Hacia adelante esa decisión significó que los gobiernos de la centroizquierda no tuvieran un paradigma económico propio, distinto al neoliberal de los Chicago Boys, lo que restó visibilidad de su gestión ante sus votantes y activistas. Hicieron varias e importantes reformas económicas que le quitaron 
el componente de radicalismo del mismo, pero que no se guiaron por otro paradigma ${ }^{10}$. Foxley se mantuvo adherido a su decisión de dar continuidad al "modelo", usando conceptos propios de los Chicago Boys, como fue declarar que la política económica del gobierno Aylwin apuntaba a tener una "economía abierta”, un objetivo para nada original pues estuvo presente desde un comienzo de la gestión de los Chicago Boys. Aún más, varios años después de dejar el gobierno y siendo senador, elogió la transformación económica de la dictadura, resaltando el papel de Pinochet y los Chicago Boys, que "cambiaron el modo de vida de todos los chilenos, para bien, no para mal. Eso sitúa a Pinochet en la historia de Chile en un alto lugar".

La Concertación sí tuvo un paradigma respecto de la cuestión militar y las violaciones a los Derechos Humanos con la política de verdad y justicia por los crímenes de la dictadura, en el cual el presidente Aylwin participó activamente en su formulación y ejecución. Sabía que era un asunto políticamente muy sensible, que tensionaría las relaciones con el general Pinochet y los militares. Sin embargo, estaba convencido que esta política era una necesidad ética y política de enfrentar para tener una democracia estable, yendo en esto más allá de la posición de Boeninger, que temía las reacciones de Pinochet contra el gobierno. Destacó la Comisión de Verdad y Reparación, conocida como Comisión Rettig, que documentó los casos que terminaron en la muerte de personas (aproximadamente 3.000 personas), entregando propuestas de reparación a los familiares de las víctimas.

Se ha sostenido insistentemente que la decisión por la continuidad del sistema económico neoliberal fue inevitable por las barreras institucionales impuestas por la Constitución de 1980, entre las cuales estaban los senadores designados, que impidió a la Concertación tener mayoría en la cámara alta (Garretón, 2012; Hagopian, 2004, 2005; Weyland, 1997). Además, se debía respetar la institucionalidad heredada porque la transición había sido por la vía de la reforma, utilizando la legitimidad legal, lo que incluiría también al sistema económico (Alberts, Warshaw y Weingast, 2012).

Nuestra tesis difiere de esta interpretación. Ello habría significado que antes de llegar a La Moneda,

10. Zahler (1984) formuló propuestas económicas en torno al paradigma de la economía mixta, dominante en las economía de Europa occidental. (Linz y Stepan, 1996). la Concertación tuvo la decisión de reformar el sistema económico heredado y, de hecho, contaba con un programa económico formulado siguiendo un paradigma distinto al de los Chicago Boys. Sin embargo, esa decisión no existió y el programa no siguió otro paradigma. Los economistas del PDC reunidos en Cieplan y en el CED (Centro de Estudios del Desarrollo), y los del PS/PPD, habían criticado la gestión económica de los Chicago Boys, pero cuando prepararon el programa de gobierno para las elecciones presidenciales de 1989, no siguieron un paradigma distinto al que orientó la política económica de la dictadura. En el caso concreto del PS, se había descuidado su definición sobre los temas económicos, pues durante la dictadura debió luchar por su sobrevivencia y luego centró sus esfuerzos en abandonar su postura revolucionaria, que no valoraba la democracia ni la vía reformista (Roberts, 1995) ${ }^{11}$. Ello llevó, en definitiva, a una indefinición respecto al sistema económico, con grandes repercusiones negativas en la sociedad chilena.

Las críticas al "modelo" formulada por los economistas de los think tanks vinculados a la oposición fueron abandonadas al aproximarse el plebiscito de 1988, para definirse a favor de la continuidad, aunque con reformas del sistema económico impuesto por la dictadura.

La primera señal en esta dirección la dieron los economistas de Cieplan en un documento publicado en el semanario Hoy en agosto de 1988, dos meses antes del plebiscito, dando una evaluación relativamente positiva de la gestión económica de los Chicago Boys ${ }^{12}$. "En estos años, escriben, "se ha reducido fuertemente la inflación, se ha eliminado finalmente el déficit fiscal y se han incrementado significativamente las exportaciones. Éstos tres factores, de suyo positivos, le permitirían al gobierno democrático iniciar una nueva etapa sin los agudos desequilibrios macroeconómicos heredados por otros países que han transitado recientemente la democracia" ${ }^{13}$. Agregan que se habrían producido "convergencias y consensos" en importantes ámbitos de la política económica, destacando la "creati-

11. La Declaración de Principios del PS de diciembre de 1990 se concentra en definiciones estrictamente políticas, sin referirse a a temas económicos.

12. Fue publicado después en "Documento, Revista de Cieplan. Nr. 14, Noviembre 1988, pp. 36-44, el texto empleado en este artículo. Sobre los antecedentes de este documento, véase Morales y Garber Fuentes (2017).

13. “El consenso económico-social”, p.39. 
vidad y espíritu emprendedor; disciplina macroeconómica; y tratamiento de la deuda externa"14.

Ahora bien, la continuidad del "modelo" no fue rígida, porque hubo reformas, de primer y de segundo grado en la formulación de Hall (1993), que eliminaron algunos elementos del radicalismo del paradigma neoliberal, pero apuntaban hacia un cambio del paradigma por otro. Los mayores cambios se hicieron en el gobierno de Aylwin, con la política para reducir la pobreza con activa intervención del Estado, marcando una diferencia con la política de los Chicago Boys, que entregaron esa tarea al mercado a través de la política del "chorreo". Se logró aprobar una reforma tributaria, aumentando el impuesto a las empresas y el IVA, para financiar la política social y una reforma laboral, para recuperar derechos de los trabajadores y de los sindicatos, que habían sido eliminados por la dictadura. Prueba de esta continuidad y cambio en la política económica del gobierno de Aylwin son las valoraciones de la política económica que hacen los grandes empresarios, como es el caso de un expresidente de la SOFOFA, quien señala poco antes del estallido social que, “(...) el gobierno de Aylwin fue más político, de transición, pero él logró que las cosas fueran los suficientemente suaves (...) y había conciencia en el modelo económico, bueno y el "loco" de Foxley, porque creo que terminó bajando los aranceles... pero si era una cuestión impensable jera más Chicago Boys que los otros! Porque era el pensamiento económico moderno, era continuidad y en algunas cosas que él estimó que había que profundizar más, las profundizó, en lo laboral hizo reformas para el otro lado (Osorio Rauld, 2020, p. 191).

Finalmente, otra política relevante de cambio fue la del Banco Central, organismo autónomo, que actuó en estrecha relación con el ministerio de Hacienda, impuso controles a los flujos de los capitales internacionales, frenando así los llamados 'capitales golondrinas' (Ffrench-Davis, 2018).

La preocupación reformista del sistema económico heredado se interrumpió con el gobierno de Frei Ruiz-Tagle, que no tuvo un programa de reformas. El presidente Frei Ruiz-Tagle, era un ingeniero que trabajó en una de las principales empresas constructoras (Sigdo Koppers), llegando a ser uno de sus socios. Durante su mandato mantuvo una cercana relación con el sector empresarial, par-

14. Ibídem, pp. 42-44. ticularmente de la construcción. Su ministro de Hacienda, Eduardo Aninat, con un doctorado en la Universidad de Harvard e investigador de Cieplan algunos años, estaba ligado al sector privado y no tuvo la preocupación reformista de su antecesor, Alejandro Foxley. Durante su gobierno, Frei Ruiz-Tagle profundizó la lógica economicista con la privatización de empresas eléctricas, una de las cuales fue Colbún, con la cual se buscaba diversificar la generación eléctrica, concentrada en dos empresas, Chilgener y Endesa, que terminó siendo abortada en sus fines por la obstrucción de Chilectra, la principal empresa distribuidora. Sus altos ejecutivos amenazaron a los consorcios extranjeros que viajaron al país a informarse sobre la privatización que no transmitirían la electricidad a la región metropolitana, que desistieron de participar en la licitación. En definitiva, fue adquirida por un grupo belga, asociado con el grupo económico Matte, que posteriormente compró el capital de aquel, que le permitió expandirse al sector eléctrico, ampliando sus intereses, hasta ese momento concentrados en la celulosa y la fabricación de papel. El presidente Frei también privatizó las empresas sanitarias y extendió las privatizaciones hacia la educación básica y media, con subvenciones a inversionistas privados. Además, dio un fuerte impulso a la privatización de las obras públicas, iniciada en el gobierno de Aylwin, entregando en concesión la construcción y administración de autopistas urbanas e interurbanas a empresas privadas.

La política de privatización continuó durante el gobierno de Lagos, acentuando la privatización de la educación superior iniciada por la dictadura, con la fundación de universidades privadas, a través de una política de expansión de la matrícula con créditos bancarios con aval del Estado (CAE), para hacer posible que los hijos de las familias de estratos populares pudieran acceder a ella y así reducir las desigualdades. Tuvo presente la política del presidente Bill Clinton en EE.UU. (1993-2001), que profundizó la privatización de la educación superior iniciada por el gobierno de Ronald Reagan (1981-1989), con la disminución de los fondos federales para becas a los estudiantes, dando inicio a un progresivo paso a créditos a los estudiantes para costear el acceso y los estudios, ello en momentos en que aumentaba fuertemente el valor de la matrícula. Clinton privatizó el principal ente estatal que otorgaba créditos a los estudiantes, aumentando el endeudamiento de millones de familias y, con ello, acrecentando las desigualdades (Mettler, 2009; 2014). La política del CAE también 
falló en las cuestiones regulatorias porque no se establecieron disposiciones claras para controlar la calidad de la educación superior que se promovía, que llevaría a casos de tráfico de influencias y corrupción que terminaron en tribunales de justicia, que dañaron aún más la credibilidad. No se explican las movilizaciones estudiantiles del 2011 y el estallido social del 2019 sin considerar al CAE, que llevó al endeudamiento de decenas de miles de familias y a la frustración estudiantil por la mala calidad de la educación.

\section{LA POLITICA DEL CONSENSO Y SUS CONSECUENCIAS EN LOS PARTIDOS}

Finalmente, la tercera decisión acordó seguir una política del consenso en la agenda económica, con la singularidad que esta no sería por breve tiempo, sino que sería permanente, incluso cuando la democracia estuviese consolidada. Esta decisión tuvo considerable relevancia política porque la continuidad del sistema económico heredado no fue impuesto por el veto de la minoría consagrado en la Constitución, sino que fue con el beneplácito de los economistas de gobiernos de la Concertación, que evitaron a la minoría de derecha tener que ejercer su poder de veto. En tal sentido, como se ha dicho, los economistas de Cieplan se habían manifestado públicamente a favor del consenso sobre el sistema económico en un documento de agosto de 1988, escasas semanas antes del plebiscito sucesorio de 5 de octubre y sin consultar a la directiva del PDC.

Lo anterior es coherente con las posturas de Ignacio Walker, ex ministro del gobierno de Lagos, ex senador (2001-2009) y ex presidente del PDC (2012-2015) e investigador de Cieplan, quien reivindicó y continúa reivindicando la continuidad del consenso: " Los cuatro gobiernos de la Concertación tuvieron como eje central de acción la democracia de los consensos básicos, la opción de crecimiento con equidad y la apertura externa con una clara postura en favor de la gradualidad de los cambios, en un sentido reformista" (Walker, 2020, p. 166).

La política del consenso fue reforzada por otros dos mecanismos, que limitaron la competencia política en Chile y que destaca Bartolini (2000) para lograr ese objetivo. El primero, fue remover de la agenda pública temas y conceptos que fueran discordantes con el consenso económico. Ello ocurrió con temas tales como desigualdades, sindicatos, reforma tributaria y concentración económica. En los debates ${ }^{15}$ sobre el estallido social del 18 de octubre de 2019, intelectuales de derecha y de la ex Concertación coincidieron en referirse únicamente a los hechos de violencia, quitándole importancia al malestar existente en la sociedad. El segundo mecanismo, agrega el mismo autor, es oscurecer las diferencias en las políticas públicas, reduciéndolas a opciones simplificadas, que concitan el interés de todos, sin ganadores y perdedores. Las políticas para combatir la pobreza, los "temas país", la "agenda público-privado", constituyeron ámbitos de políticas públicas con lo cual reforzaban la adhesión al consenso respecto de reforzar la decisión por la continuidad del sistema económico.

Los partidarios del consenso permanente desconocieron sus consecuencias negativas en la competencia política y en los partidos, algo que no ocurrió, por ejemplo, en otras latitudes como en España, con el primer gobierno democrático del presidente del gobierno Adolfo Suárez (UCD) y el PSOE, el principal partido de la oposición. En ese país, se dio por terminada dicha política con la ratificación de la nueva Constitución en el referéndum de diciembre de 1978, dando por iniciada la competencia política, que se expresaría en la campaña electoral para las elecciones municipales en abril de 1979 y en las elecciones autonómicas realizadas posteriormente (Huneeus, 1985; Powell, 2001). Este ejemplo dista mucho del caso chileno, en el que la política del consenso fue perjudicial para la competencia política y para los partidos. En efecto, la competencia política requiere que los temas de la campaña electoral sean claros para los votantes y puedan distinguir las diferencias entre las propuestas de los candidatos (Bartolini, 1999). No basta que en la competencia electoral hubiese varios candidatos de distintos partidos; también se necesitaba que sus propuestas fuesen discernibles para el elector. Si ello no ocurre, la decisión electoral de la ciudadanía se basará en la simpatía o antipatía al candidato, sin tomar en cuenta razones políticas, que son definitorias de la representación (Bartolini, 2000).

En definitiva, el consenso fue perjudicial para el PDC y el PS porque no pudieron perfilar sus identidades programáticas e históricas. EI PDC tenía una

15. Alejandro Foxley, responsable del programa económico de la senadora Carolina Goic, candidata presidencial del PDC en las elecciones de 2017, Ilamó directamente a dejar de lado el problema de las desigualdades porque "va a abrumar a la gente" . La Segunda, 4 de julio de 2017. 
historia positiva antes del golpe militar, con el gobierno de Eduardo Frei Montalva, recordado especialmente por su reforma agraria (Gazmuri, 2000). Su hijo, Eduardo, fue elegido senador en 1989 y presidente en 1993 con la ayuda de la memoria de su padre. Sin embargo, la DC renunció a un importante recurso de la competencia electoral.

Además, en democracia, la DC enfrentaba la competencia de la derecha, que no la tuvo el partido antes de 1964, con el desplome de liberales y conservadores en el gobierno de Jorge Alessandri (1958-1964), que llevó a que su electorado votara por Frei en la elección presidencial. En las elecciones parlamentarias de 1989, el PDC alcanzó el $25,99 \%$ de los votos, inferior al recibido en las en las elecciones de marzo de 1973, 28,7\%, las últimas antes del golpe militar. La derecha, con RN y UDI, recibió $33,2 \%$ de los votos, muy superior al $21 \%$ que alcanzó en los comicios de 1973 el Partido Nacional, fundado después de la disolución de los partidos históricos (Cruz-Coke, 1984). En consecuencia, la DC tenía una amenaza por la derecha que fue desconocida por la tecnocracia, pero también por las directivas del partido.

\section{LOS SILENCIOS DE LA TECNOCRACIA}

La tecnocracia concertacionista desconoció el contexto político de la transformación económica de la dictadura. No es indiferente el contexto en el cual se realiza una transformación económica, en democracia o en dictadura. En la primera, como la que llevó a cabo el gobierno conservador de Margaret Thatcher (1979-1990) en Gran Bretaña, se hizo con Estado de derecho, con transparencia, a través de convocatorias internacionales y con estrictas limitaciones a los ejecutivos y trabajadores para comprar acciones y sin discriminaciones a favor de los altos ejecutivos de las empresas estatales (Florio, 2004). Antes de las privatizaciones, establecieron regulaciones, con fuertes órganos que buscaban se respetaran las normas, para impedir que los monopolios estatales fueran monopolios privados (Hall, 1986; Majone, 1993).

En la dictadura chilena, el contexto político fue enteramente diferente y esto marcaría la arquitectura institucional del sistema económico y la cultura económica de los empresarios. No hubo Estado de derecho, rigió el secretismo y no hubo igualdad en el mercado, porque se benefició, especialmente con las privatizaciones, a los altos ejecutivos de las empresas y colaboradores del equipo económico, siguiendo un paradigma de neoliberalismo radical, que tuvo, como ya dijimos, una visión totalizante y no fue neutral políticamente. Desmanteló el Estado empresario a través de las privatizaciones, que abarcó la venta de las empresas públicas creadas desde los años 40, incluidas las empresas estatizadas por el gobierno de la Unidad Popular (Marcel, 1989) y las empresas que pasaron a control del Estado por haber quebrado por la crisis económica de 1982, constituyendo el "área rara" de la economía (Huneeus y Undurraga, 2021). A diferencia del caso inglés, no se establecieron regulaciones antes de las privatizaciones, lo que favoreció el desarrollo de tendencias monopólicas y de concentración económica, el fortalecimiento de grupos económicos históricos y la formación de nuevos conglomerados. Eso permitió la conformación de una élite empresarial acostumbrada a actuar sin injerencia del Estado en la economía. Surgieron, además, poderosas organizaciones gremiales que en democracia actuarían como activos grupos de presión para promover políticas ante las autoridades y ante la opinión pública, dirigidas a justificar la continuidad del "modelo socioeconómico" (Osorio, 2019).

Las privatizaciones de los años 80 (empresas públicas y del "área rara" de la economía), incluyeron incentivos para que compraran acciones pequeños inversionistas y profesionales ("el capitalismo popular"), los cuales obtuvieron en pocos años utilidades significativas, lo cual aumentó el número de los beneficiarios del "modelo", más allá del reducido número de personas que participaron directamente en la venta de las empresas.

Finalmente, las privatizaciones, además, abarcaron el sistema de pensiones reemplazándolo por uno de capitalización individual, con las AFP (Administradoras de Fondos de Pensiones), instituciones privadas con fines de lucro, cuyos fondos de los trabajadores serían utilizados en las tres privatizaciones impulsadas desde 1985 para financiar la compra de acciones (Hachette y Lüders, 1992; Huneeus, 2000). Con la expansión económica en democracia y las políticas de continuidad del "modelo", los fondos de las AFP aumentarían de una manera exponencial, siendo administrados por instituciones financieras logrando considerables utilidades y beneficios indirectos, en términos de la influencia en el sistema financiero (Tromber, 2016). Al 28 de febrero de 2020, los fondos de pensión de las AFP alcanzaban el monto de US $\$ 195.130$ millones de dólares, lo que equivalía al $80,7 \%$ del PIB de Chile ${ }^{16}$.

16. Datos de la Superintendencia de AFP. 
Esta monumental transferencia de recursos del Estado a privados reforzaría las bases estructurales de las desigualdades, que sobresalen a nivel internacional. Estas se deberían medir no por las encuestas de ingreso (que subestiman a las personas de más altos ingresos) sino por las declaraciones de impuestos. Como lo han mostrado varios autores (Inglehart, 2016), las desigualdades no se miden por deciles, como lo hacen los estudios basados en encuestas de ingreso, sino por el 1\% y hasta un porcentaje menor, mostrando la riqueza de los superricos. El 1\% más rico de Chile tiene un $28,7 \%$ del ingreso nacional, superior al de EE.UU. $(20,4 \%)$ y cuatro veces el de España $(8,6)$. También es altísimo el porcentaje que reúne el 0,1\% (los notables económicos según Dahl (1961)) y el 001\%, unas 1750 personas en el país. Solamente Brasil y México se acercan a las desigualdades de Chile.

En definitiva, se puede señalar que la tecnocracia de la Concertación ignoró esta realidad de las desigualdades, una consecuencia de no haber considerado la arquitectura institucional del sistema económico, el principal legado de la dictadura, junto con la Constitución de 1980. Como la Convención Constitucional está redactando una nueva Constitución, que deberá ser ratificada en un referéndum el 2022, el sistema económico de mercado puro (Linz y Stepan, 1996) sigue siendo el principal obstáculo para alcanzar a tener una democracia moderna, es decir, avanzar de una democracia semisoberana a una democracia soberana. Veremos, en lo que sigue, si este actor institucional logra realizar esta anhelada transformación demandada por la ciudadanía, permitiendo a Chile dejar atrás el legado autoritario que ha contribuido a socavar las bases culturales de la democracia.

\section{A MODO DE CONCLUSIÓN}

El cambio de régimen constituye una "coyuntura crítica' durante la cual se adoptan decisiones que definen las instituciones y las políticas (policies), las cuales perduran en el tiempo. Las instituciones pueden sufrir cambios, sea para ajustarse a las exigencias de la coyuntura histórica, bien para reformarse con el fin de corregir limitaciones y falencias que les permitan enfrentar nuevos desafíos, o bien, para rectificar su rumbo y seguir en otra dirección. Estas posibilidades de reformas no son fáciles porque los resultados logrados le confirman a las instituciones que van por un buen camino, adquiriendo una inercia que reforzará su dirección (Pierson, 2000). Esta inercia conduce a rigidez institucional, que impide advertir sus limitaciones y es fuente de tensiones y conflictos.

En este trabajo hemos analizado la política económica de los gobiernos de la Concertación, que tuvo una gran continuidad durante dos décadas, examinando el papel de la tecnocracia, que jugó un papel clave en su definición e implementación. Lo hicimos revisando sus decisiones estratégicas, la principal de las cuales fue la continuidad del sistema económico heredado de la dictadura, que corresponde a una economía de mercado puro, en la tipología de Linz y Stepan (1996), que es incompatible con la democracia. El estallido social confirmó la validez de la advertencia de estos autores. El trabajo ha entregado antecedentes para identificar sus causas, que son legados de la dictadura y políticas de los gobiernos democráticos, que no tuvieron la visión para advertir las limitaciones y carencias del "modelo", que provocaron desencanto y malestar en la mayoría de la población.

Para tener una democracia estable, agregan Linz y Stepan, es necesario tener una sociedad económica, para lo cual se requiere impulsar reformas institucionales que reemplazarán la economía de mercado puro. Chile debiera seguir este camino si desea tener una democracia estable. La nueva Constitución seguramente contendrá disposiciones que apunten hacia el establecimiento de una sociedad económica, pero corresponderá al próximo gobierno traducir esas normas en políticas en la construcción de una sociedad de este tipo. Entre estas, no podrá estar ausente las que disminuyan las desigualdades, el nuevo clivaje que marcará la política durante el siglo XXI, como lo fue el conflicto de clases durante el siglo XX.

\section{REFERENCIAS}

Agostinl, C. (2012). Financiamiento de la Política en Chile: campañas electorales de 2009-2010. En F. J. Díaz y L. Sierra (Eds,), Democracia con partidos. Informe para la reforma de los partidos políticos en Chile (pp. 269-319). CEP-Cieplan.

AgüERo, F. (1995). Soldiers, civilians, and democracy: Post-Franco Spain in comparative perspective. The John Hopkins University Press.

Alberts, S., Warshaw, C. y Weingast, B. (2012). Democratization and Countermajoritarian Institutions: Power and Constitutional Design in Self-Enforcing Democracy. En T. Ginsburg (Ed.). Comparative Constitutional Design (pp. 69-100). Cambridge University Press. 
Arriagada, G. y Graham, C. (1994). Chile: Sustaining Adjustment during Democratic Transition. En S. Haggard y S. Webb (Ed.). Voting for Reform (pp. 242-289). Oxford University Press.

BARTOLINI, S. (1999). Collusion, competition, and Democracy Part I. Journal of Theoretical Politics, 11(4), 435-470. https://doi. org/10.1177/0951692899011004001

BartolinI, S. (2000). Collusion, competition, and Democracy Part II. Journal of Theoretical Politics, 12(1), 33-65. https://doi. org/10.1177/0951692800012001002

Bermeo, N. (1992). Democracy and the Lessons of Dictatorship. Comparative Politics, 24(3), 273291. https://doi.org/10.2307/422133

Bitar, S. (1979). Transición, socialismo y democracia: la experiencia chilena. Siglo XXI.

Boeninger, E. (1997). Democracia en Chile. Lecciones para la gobernabilidad. Editorial Andrés Bello.

Boeninger, E. (2007). Políticas públicas en democracia. Institucionalidad y experiencia chilena 1990-2006. Cieplan-Uqbar Editores.

Caramani, D. (2017). Will vs. Reason: The Populist and Technocratic Forms pf Political Representation and Their Critiques to Party Government. American Political Science Review, 111(1), 54-67. https://doi.org/10.1017/S0003055416000538

CAStiglioni, R. y Rovira, C. (2016). Introduction. Challenges to Political Representation in Contemporary Chile. Journal of Politics in Latin America, 8(3), 3-24. https://doi. org/10.1177/1866802X1600800301

Concertación de Partidos por la Democracia (1989). Programa de Gobierno Concertación de Partidos por la Democracia. Repositorio Digital Archivo Patricio Aylwin Azocar. http://www2.archivopatricioaylwin.cl/handle/123456789/7626

Correa SutiL, J. (1997). No Victorious Army Has Ever Been Prosecuted...: The Unsettled Story of Transitional Justice in Chile. En A. J. McAdams (Ed.). Transitional Justice and the Rule of Law in New Democracies (pp. 123-154). University of Notre Dame Press.

Cruz-Coke, R. (1984). Historia electoral de Chile 1925-1973. Editorial Jurídica de Chile.

DAHL, R. (1961). Who governs? Democracy and Power in an American City. Yale University Press.

Dávila, M. (2020). Presidencialismo a la chilena. Coaliciones y cooperación política. 1990-2018. Editorial Universitaria.

Dezalay, Y. y Bryant, G. (2002). The Internationalization of Palace Wars. Lawyers, Economists, and the Contest to Transform Latin American States. The Uni- versity of Chicago Press. https://doi.org/10.7208/ chicago/9780226144276.001.0001

Domínguez, J. (1997). Technopols: Ideas and Leaders in freeing Politics and Markets in Latin America in the 90s. En J. Domínguez (Ed.). Technopols. Freeing Politics and Markets in Latin America in the 1990s (pp. 1-48). The Pennsylvania University Press.

Foxley, A. (1985). Para una democracia estable. Economía y política. Editorial Aconcagua-CIEPLAN.

FFrench-Davis, R. (2018). Reformas económicas en Chile, 1973-2017. Taurus.

GÁrate, M. (2012). La revolución capitalista en Chile (1973-2003). Ediciones Universidad Alberto Hurtado.

Garretón, M. A. (2012). Neoliberalismo corregido y progresismo limitado. Los gobiernos de la Concertación en Chile, 1990-2010. Editorial ArCis-CLACSO.

GazmuRl, C. (2000). Eduardo Frei Montalva y su época. Aguilar.

HACHETTE, D. y LüdeRS, R. (1992). La privatización en Chile. Centro Internacional para el Desarrollo Económico, CINDE.

HAGopian, F. (2004). Authoritarian Legacies and Market Reforms in Latin America. En K. Hite y P. Cesarini (Eds.). Authoritarian Legacies and Democracy in Latin America and Southern Europe (pp. 85-158). University of Notre Dame Press.

Hagopian, F. (2005). Chile and Brazil. En L. Diamond y L. Morlino (Eds.). Assessing the Quality of Democracy (pp. 123-162). The Johns Hopkins University Press.

HaLL, P. (1986). Governing the Economy: The Politics of State Intervention in Britain and France (Europe and the International Order). Oxford University Press.

Hall, P. (1993). Policy Paradigms, Social Learning and the State: The Case of Economic Policymaking in Britain. Comparative Politics, 25(3), 275296. https://doi.org/10.2307/422246

Huneeus, C. (1985). La Unión de Centro Democrático y la transición a la democracia en España. Centro de Investigaciones Sociológicas-Siglo XXI Editores.

Huneeus, C. (1996). Economía y democracia. ¿Es estable el crecimiento con insuficiente desarrollo político?. El Mercurio, 24 de noviembre, D30-31. Huneeus, C. (1997). ¿Una democracia sin partidos?. El Mercurio, 21 de diciembre, A2.

Huneeus, C. (1998). Malestar y desencanto en Chile. Legados del autoritarismo y costos de la transición". Papeles de Trabajo, 63, Corporación 
Tiempo 2000.

Huneeus, C. (2003). Chile, un país dividido. La actualidad del pasado. Catalonia.

Huneeus, C. (2014). La democracia semisoberana. Chile después de Pinochet. Taurus.

Huneeus, C. (2000). El régimen de Pinochet. Editorial Sudamericana.

Huneeus, C., Cuevas, R. y Hernández, F. (2014). Los centros de investigación privados (think tank) y la oposición al régimen autoritario chileno. Revista Uruguaya de Ciencia Política, 23(2), 19-37.

Huneeus, C. y Couso, J. (2016). Eduardo Frei Montalva: un gobierno reformista. A 50 años de la "Revolución en Libertad". Editorial Universitaria.

Huneeus, C. y Pastén, M. (2020). ¿Crisis del presidencialismo o crisis de la presidencia? El liderazgo presidencial de Sebastián Piñera. Revista Chilena de Derecho y Ciencia Política, 11(2), 145-176. https://doi.org/10.7770/rchdcp-V11N2-art2335

Huneeus, C. y UndurRaga, T. (2021). Authoritarian Rule and Economic Groups in Chile: a Case of Winner-takes-all Politics. En V. Basualdo, H, Berghoff y M. Bucheli (Eds.), Big Business and Dictatorships in Latin America. A Transnational History of Profits and Repression (pp. 91-125). Palgrave Macmillan. https://doi.org/10.1007/978-3030-43925-5_4

INGLEHART, RONALD (2016). "Inequality and Modernization. Why Equaliy is Likely to Make a Comeback". Foreign Affairs. 95, pp. 2-10.

Jara, S. (2018). Piñera y los leones de Sanhattn. Crónica del auge de la élite financiera chilena. Planeta.

Joignant, A. (2011). The Politics of Technopols: Resources, Political Competence and Collective Leadership in Chile. 1990-2010. Journal of Latin American Studies, 43, 517-546. https://doi. org/10.1017/S0022216X11000423

LAGos, R. (1960). La concentración del poder económico. Editorial del Pacífico.

LIJPHART, A. (2001). Democracy in the 21st century: can we be optimistic? European Review, 9(2), 169-184. https://doi.org/10.1017/ S1062798701000163

Linz, J. y Stepan, A. (1996). Problems of Democratic Transition and Consolidation. The John Hopkins University Press.

LIPSET, S. M. (1960). Political Man. Heinemann.

LunA, J. P. (2016). Chile's crisis of Representation. Journal of Democracy. 27(3), 129-138. https://doi.org/10.1353/jod.2016.0046

Luna, J. P. (2017). En vez del optimismo. Crisis de representación política en el Chile actual. Ciper-Catalonia.

Majone, G. (1994). The Rise of the Regulatory State in Europe. West European Politics, 17(3), 77-101. https://doi.org/10.1080/01402389408425031

MaIR, P. (1994). Party Organizations: From Civil Society to the State. En R. S. Katz y P. Mair (Eds.). How Parties Organize. Change and Adaptation in Party Organizations in Western Democracies (pp. 1-22). Sage Publications Ltd. https://doi. org/10.4135/9781446250570.n1

MalR, P. (2015). Gobernando el vacío. La banalización de la democracia occidental. Alianza Editorial.

Marcel, Mario (1989). Privatización y finanzas públicas: el caso de Chile 1985-1988. Estudios CIEPLAN 26, 5-60.

MaYoL, A. (2013) El derrumbe del modelo. La crisis de la economía de mercado en el Chile contemporáneo. Lom ediciones.

MayoL, A. (2019) Big Bang Estallido social 2019: Modelo derrumbado - sociedad rota - política inútil. Catalonia.

MerkeL, W. (1999). Defective Democracies. Estudio/ Working Paper 132. Centro de Estudios Avanzados en Ciencias Sociales, Instituto March de Estudios e Investigaciones.

Mettler, S. (2009). Promoting Inequality: The Politics of Higher Education Policy in an Era of Conservative Governance. En L. Jacobs y D. King (Eds.). The Unsustainable American State, (pp. 197-222). Oxford University Press. https://doi.org/10.1093/acprof:oso/9780195392135.003.0008

Mettler, S. (2014). Degrees of Inequality. How The Politics of Higher Education Sabotaged the American Dream. Basic Books.

Montecinos, V. (1990). Economists and Democratic Transition: The Quest for Governability in Chile. En D. Ethier (Ed.). Democratic Transition and Consolidation in Southern Europe, Latin America and Southeast Asia (pp. 91-109). Macmillan. https://doi.org/10.1007/978-1-349-11412-2_5

Montecinos, V. (1998) Economists, Politics, and the State: Chile 1958-1994. CEDLA.

Montero, C. (1993). El actor empresarial en transición. Colección Estudios Cieplan, (37), 822-834.

Morales, J. J. (2018). Dominación filantrópica y gobernabilidad democrática: el caso de la fundación Ford y Cieplan en Chile (1976-1990). Historia, 51(1), 141-163. https://doi.org/10.4067/ s0717-71942018000100141

Morales, J. J. y Garber, C. (2017). El consenso eco- 
nómico-social democrático fue posible. El papel de los economistas de Cieplan en el Chile de la transición (1988-1991). MILLCAYAC - Revista Digital de Ciencias Sociales, IV(7), 71-94.

Morales, M. (2018). Elecciones y participación en Chile (1988-2017). En C. Huneeus y O. Avendaño (Eds.). El sistema político de Chile (pp. 225258). Lom Ediciones.

Muñoz, O. (2007). El modelo económico de la Concertación 1990-2005. ¿Reformas o cambio? FLACSO Chile-Catalonia.

Osorio Rauld, A. (2019). iQue se vayan todos, que no quede uno solo! La crisis institucional en Chile: factores contributivos del socavamiento de las bases culturales de la democracia (1990-2019). Revista de investigaciones Políticas y Sociológicas, 18(2), 73-94. https://doi.org/10.15304/ rips.18.2.6375

Osorio Rauld, A. (2020). La cultura política de la élite empresarial chilena. Un análisis comparado de los dirigentes gremiales de la Sociedad Nacional de Agricultura y la Sociedad de Fomento Fabril (2018-2019) [Tesis Doctoral, Universidad Complutense de Madrid]. https://eprints.ucm. es/id/eprint/59130/.

Pierson, P. (1993). When Effect Becomes Cause: Policy Feedback and Political Change. World Politics, (45), 595-628. https://doi. org/10.2307/2950710

Pierson, P. (2000). Increasing Returns, Path Dependence, and the Study of Politics. American Political Science Review. 94(2), 251-267. https://doi. org/10.2307/2586011

Powell, C. (2001). España en democracia 19752000. Plaza \& Janes.

Puryear, J. M. (1994). Thinking Politics. Intellectuals and Democracy in Chile, 1973-1988. The Johns Hopkins University Press.

Roberts, K. M. (1995). From the Barricades to the Ballot Box: Redemocratization and Political Realignment in the Chilean Left. Politics \& Society, 23(4), 485-519. https://doi. org/10.1177/0032329295023004005

Scarrow, S. E. y Webb, P. (2013). Assessing Party Organizational Change: Participation, Representation and Power. Reunión anual American Political Science Association.

SCHUMPETER, J. A. (1984). Capitalismo, socialismo y democracia. Ediciones Folio.

Silva, P. (2008). In the Name of reason. Technocrats and Politics in Chile. The Pennsylvania State University Press.

Stepan, A. (1988). Rethinking Military Politics.
Princeton University Press. https://doi. org/10.1515/9780691219639

Stipicic, C. y BarRía, C. (2017). La segunda transición. Conversaciones con Alejandro Foxley. Uqbar Editores.

Strom, K. (2000). Parties at the Core of Government. En R. Dalton y M. Wattenberg (Eds.). Parties without Partisans. Oxford University Press.

Tromben, C. (2016). Crónica secreta de la economía chilena. Ediciones B Chile S.A.

WaLkER, I. (2020). Pasión por lo posible. Aylwin, la transición y la Concertación. Ediciones Universidad Diego Portales.

WeYLAND, K. (1997). Growth with Equity in Chile's New Democracy. Latin American Research Review, 32(1), 37-67.

Wildemann, R. (1986). The Problematic of Party Government. En F. C. Castles y R. Wildemann (Eds.). Visions and Realities of Party Government (pp. 1-30). Walter de Gruyter. https://doi. org/10.1515/9783110904000.1

Wolinetz, S. B. (2002). Beyond de Cath-All-Party: Approaches to the Study of Parties and Party Organization in Contemporary Democracies. En R. Gunther, J. Ramón y J. Linz (Eds.). Political Parties. Old Concepts and New Challenges (pp. 136-165). Oxford University Press. https://doi. org/10.1093/0199246742.003.0006

ZAHLER, R. (1984). Economía mixta: exigencia del régimen democrático. En $\mathrm{E}$. Boeninger (Ed.). Orden económico y democracia (pp. 237-291). Centro de Estudios del Desarrollo. 